\section{Investigation on the effects of vermiculite-based feed additives on ammonia and nitrate emission from pig slurry and pig growth performances}

\author{
Riccardo Consigliere, ${ }^{1}$ Annamaria Costa, ${ }^{2}$ \\ Domenico Meloni ${ }^{3}$
}

1Faculty of Medical and Veterinary Sciences, Division of Farm Animal Science, University of Bristol, Bristol, Langford, UK; 2Department of Health, Animal Science and Food Safety, University of Milan; ${ }^{3}$ Department of Veterinary Medicine, University of Sassari, Italy

\section{Abstract}

The aim of the present study was to evaluate the effects of vermiculite-based feed additives used in fattening pigs on the concentrations of nitrogen compounds in manure and atmosphere and upon measures of pig production efficiency. The trial was conducted in a fattening unit representative of Italian commercial units. The pigs were routinely fed twice a day with a feed ration identical for all the pigs except for the addition of the vermiculite additive (group A). During the fattening period, the evolution of atmospheric ammonia concentration, total nitrogen, ammonia and nitrates of slurry and pigs live weight gain were evaluated. The inclusion at very low dosage of vermiculite-based feed additives in fattening pigs increased the nitrification activity in the treated slurry. No reduction of the ammonia emission was obtained. The average growth rate of the treated group was higher, whilst the feed conversion rate was similar in both groups.

\section{Introduction}

Intensive pig production systems produce large amounts of waste contributing to land, air and water pollution, the origin and level of polluting substances have been monitored in many countries. Wathes ${ }^{1}$ has described the dynamics of aerial pollutants in pig houses and has identified in dust and emission gaseous compounds of low molecular weight arising from slurry the two main causes of environmental pollution as well as of deterioration of human and animal welfare condition. For this reason it is now an important goal for the whole pig industry to reduce effectively the emission of such compounds. To achieve this reduction several techniques for abatement and control have been trialed, however the production and emission of polluting gasses and dust are still difficult to keep under control. Previous authors investigated ways to reduce polluting compounds arising from slurry by modifying the composition of urine and feces mainly through modification of diet, in fact several papers ${ }^{2-5}$ have shown that lowering the crude protein (CP) content in the diet and thus the $\mathrm{N}$ intake can reduce significantly the urea and total $\mathrm{N}$ excretion. Others research groups increased the dietary crude fiber content to obtain similar results of reduced nitrogen excretion. ${ }^{6-8}$ Therefore it has been well established that applying multiphase feeding at reduced $\mathrm{CP}$ levels and increasing fiber content can achieve a highly significant reduction of $\mathrm{N}$ excretion. However the majority of pig producers tend to use a single feed throughout the entire rearing period, as it is perceived to be cheaper and simpler to control. As a consequence, the concentrations of excreted nitrogen in the manure increases progressively as time passes and feed energy is not utilized efficiently by the pigs. Due to this fact, some authors have focused their attention on the use of feed additives to obtain similar results, in particular feeding zeolite minerals to growing pigs to reduce intestinal absorption of ammonium (a) or (salts) and the conversion of ammonium to urea, which resulted in reduced excretion of nitrogen with urine.9,10 Vermiculite-based feed additives have been developed with enhanced cation exchange capacity, thus supposed to be more efficient than other clay minerals, however, no literature is available showing the effects of vermiculite neither on the reduction of emission of polluting compounds from slurry nor on the possible repercussion of the inclusion of vermiculite in the diet on production performances. In the majority of the investigations using other clays (tectosilicates), the levels of inclusion were between 2 and $10 \%$ of the feed weight, the inclusion rate of vermiculite used in this trial was $0.007 \%$. Hence, the present survey aimed to establish the effects of vermiculite-based feed additives used in fattening pigs under commercial conditions, on the concentrations of nitrogen compounds in manure and atmosphere surrounding the pigs and upon measures of pig production efficiency.

\section{Materials and Methods}

\section{Experimental design}

The trial was conducted over a 5 months period from the beginning of March to the first 15 days of July, in a fattening unit representative of Italian commercial units. All the pigs
Correspondence: Domenico Meloni, Department of Veterinary Medicine, University of Sassari, Via Vienna 2, 07100, Sassari, Italy.

Tel: +39.079 .229 .570 . Fax: +39.079 .229 .458 .

E-mail: dmeloni@uniss.it

Key words: Vermiculite-based feed additives; growth performance.

Contributions: RC, substantial contribution to conception and design, acquisition of data; AC, substantial contribution to statistical analysis, DM, substantial contribution to conception and design, drafting the article or revising it critically for important intellectual content.

Conflict of interest: the authors declare no potential conflict of interest.

Received for publication: 2 November 2015. Accepted for publication: 8 December 2015.

This work is licensed under a Creative Commons Attribution NonCommercial 4.0 License (CC BYNC 4.0).

(C) Copyright R. Consigliere et al., 2016 Licensee PAGEPress srl, Italy

Veterinary Science Development 2016; 6:6292 doi:10.4081/vsd.2016.6292

included in this trial were sourced from the following crossbreeding scheme: female parent: Large White-Landrace cross, male parent: Duroc pure breed. The pigs under trial were divided in two groups: treated (group A) and control (group B), by age and weight. During the growing period prior to the beginning of the trial, all the pigs were housed in two separated sites according to age criteria: from birth to the weaning the piglet were housed in the grower unit, where, within the first week of age, all the males were castrated and both males and females received an intramuscular injection of cephalosporin (Ceftiofur ${ }^{\circledR}$ ) and Fe destrane; the pigs started the weaning period at 21 days having reached average body weight of $6 \mathrm{~kg}$, at this stage they all received a second intramuscular injections of cephalosporin and the mycoplasma one shot vaccine Ingelvac ${ }^{\circledR}$ M.hyo. During this period the animals were fed a weaning complementary feed for 15 days containing amoxicillin trihydrate (400 ppm), colistin sulphate $(120 \mathrm{ppm})$ and zinc oxide (240 ppm) until they reached the body weight of about $12 \mathrm{~kg}$, then up to the weight of $20 \mathrm{~kg}$ were fed with a starter complementary feed containing amoxicillin trihydrate (300 ppm) and colistin sulphate (120 ppm), finally from 20 to $56 \mathrm{~kg}$ the complementary feed composition was changed as the antibiotics were removed and acetic and formic acid were added as acidity correctors. From the weight of 
$56 \mathrm{~kg}$ up to reaching the expected slaughter weight of approximately $160 \mathrm{~kg}$ all the pigs were moved to the fattening unit, which is the subject of this trial. The unit was laid out as follows: four identical barns of rectangular shape measuring $80 \times 20 \mathrm{~m}$ capable of accommodating 800 pigs each, the four buildings were laid out in two pairs aligned side by side along their major axis and separated by open space. The interior of each barn was subdivided into 40 rectangular pens with a surface of $25 \mathrm{~m}^{2}$ each aligned in two rows of 20 pens, a passageway $80 \mathrm{~cm}$ wide separated the two rows of pens. This passageway was used to inspect and handle the pigs to perform the individual live weight check. In each barn the group under trial was housed in 4 designated pens, in batches of 20 pigs, chosen at the center of the building and separated by sex. Pens 1 and 2 housed female pigs and pens 3 and 4 housed male pigs. Once housed in the designated pens the pigs were not moved out except for the weight check and on the day of slaughter. It must be highlighted that the pigs of all groups in the trial were housed during the rearing period -so up to $56 \mathrm{~kg}$ of weight- on two different kinds of floor: the group A (treated) was used to living on a fully slatted floor, whereas the group B (control) was used to living on a solid floor with access to a defecation area on slats and thus a condition similar to the trial unit. All four barns were managed identically and pigs were routinely inspected twice a day by a trained stockman to check health conditions. The pigs were routinely fed twice a day a liquid broth pumped in the feed trough automatically, the water was available ad libitum by mean of nipple drinkers fitted in each holding pen, the composition of the feed ration was identical for all the pigs except for the addition of the vermiculite additive which had been regularly incorporated since the day of arrival at the fattening unit only in the receptacle dedicated to fill the troughs of barn number 4, the components of the diet mix are detailed in Table 1.

\section{Measurements of atmospheric ammonia concentration}

To evaluate air quality in the housing barns three measurements of the atmospheric ammonia concentration were taken at 50 days interval in barn 4 and 2 by means of a Draeger Tube apparatus (Draeger Instrument Safety, Inc., Pittsburgh, PA, USA). During measurements the sensor was placed at about $60 \mathrm{~cm}$ from the floor level, as it was approximately the distance of the heads of the pigs from the floor. The pigs of group A (treated) before being moved in to the fattening unit under trial were used to being housed in the rearing unit in pens fitted with fully slatted floor systems and thus were accustomed to a different excretory behavior from the pigs of group B (control). This situation was expected to cause a difference in the cleanliness of the floor which might have resulted in variations in the atmospheric ammonia concentration, thus the floor cleanliness was assessed at the same time as the atmospheric ammonia measurements by recording the number of fouled pens and the fouled area. The total fouled area was calculated from the dirty area relative to the total floor area. The environmental temperature and relative humidity were recorded by mean of a thermocouple and a hygrometer suspended at $2 \mathrm{~m}$ height at the center of barns 2 and 4 and connected with a data logger Babuc M of LSI.

\section{Measurement of total nitrogen, ammonia and nitrates of slurry}

The liquid suspension used in all tests was slurry collected from the two independent pits fitted under the slatted floor of the defecation area in barn 2 and 4 . The slurry was collected during 3 sampling sessions at 40-day intervals. The first set of samples was collected at 30 days from the introduction of the pigs in the unit; on each sampling session three slurry samples of $500 \mathrm{~mL}$ were taken from each of the two collection pit for a total of 6 samples per sampling session. The slurry was gently stirred manually before sampling to obtain a homogeneous sample and was collected with a scoop

Table 1. Qualitative and quantitative composition of the pig feed.

\begin{tabular}{lc} 
Component & $\%$ of the feed dry matter \\
Soy beans & 40 \\
Barley & 20 \\
Bran & 19 \\
Wheat middlings & 10 \\
Lard & 5 \\
Levurene 3\%@ & 6 \\
\hline Vermiculite-based feed additive & 0.007
\end{tabular}

Table 2. Average live weight (LW), average growth rate (GR) and feed conversion ratio (FCR).

\begin{tabular}{lcccccc} 
& & Group A & & & Group B \\
& LW Kg \pm SEM & GR g/day \pm SEM & FCR & LW Kg \pm SEM & GR g/day \pm SEM & FCR \\
March & 59 & - & - & 56 & - & - \\
April & $82.1 \pm 0.99 \mathrm{~A}$ & $0.797 \pm 0.096$ & 2.11 & $108.7 \pm 1.16$ & $0.518 \pm 0.008^{\mathrm{b}}$ & 3.34 \\
\hline May & $106.9 \pm 1.21$ & $0.590 \pm 0.007 \mathrm{a}$ & 3.32 & $131.6 \pm 1.54$ & $0.617 \pm 0.008^{\mathrm{b}}$ & 2.03 \\
\hline
\end{tabular}

$\mathrm{A}, \mathrm{B}$ Means in the same row bearing the same superscript differ significantly for $\mathrm{P}<0.01$. a,b Means in the same row bearing the same superscript differ significantly for $\mathrm{P}<0.05$

Table 3. Aerial concentration of ammonia gas and floor cleanliness assessment.

\begin{tabular}{|c|c|c|c|c|c|c|}
\hline & & Group A & & & Group B & \\
\hline & $\mathrm{NH}^{4} \mathrm{ppm} \pm \mathrm{SEM}$ & & & NH4 ppm $\pm s$ & EM Flo & ndition \\
\hline & & N. dirty pens & $\%$ tot. surface & & N. dirty pens & $\%$ tot. surface \\
\hline April & $8.2 \pm 1.10$ & 23 & 57 & $7 \pm 1.11$ & 18 & 45 \\
\hline May & $8.3 \pm 1.05$ & 34 & 85 & $6.6 \pm 1.05$ & 12 & 30 \\
\hline June & $15.6 \pm 1.06^{\mathrm{a}}$ & 36 & 90 & $9.3 \pm 1.10^{b}$ & 15 & 37 \\
\hline
\end{tabular}

a,bMean values bearing superscript differ significantly $(\mathrm{P}<0.05)$. 
placed in sealable container, the 6 containers were labeled, and stored refrigerated at $+3{ }^{\circ} \mathrm{C}$. From each slurry sample the following 3 parameters were measured: i) kjeldal nitrogen: two slurry specimen of the weight of $5 \mathrm{~g}$ each were processed according to the method describe in Association of Official Agricultural Chemists (AOAC) 11 by of the automated apparatus Büchi 435 digestion unit; ii) ammonia concentration was measured using a digital ion meter fitted with a gas selective diffusion electrode specific for ammonia detection in water solution, according to the standard method of AOAC;11 iii) nitrates were measured using the high pressure liquid chromatography (HPLC) according to the method of PerkinElmer Co., 12 by mean of the apparatus HPLC Perkin Elmer 200 Peltier Column with a standard loop volume of $10 \mu \mathrm{L} \mathrm{UV/visible} \mathrm{detector}$ at a wave length of $210 \mathrm{~nm}$.

\section{Measurement of the pigs live weight gain during fattening period}

The live weight check was carried out on all pigs of houses 2 and 4 on four occasions: the first weight check was performed at the day of arrival at the fattening unit and thereafter at 40 days interval, during the last weight check the pigs were individually marked with a slap mark on the shoulder to enable carcass identification at the abattoir. The weight check was carried out using an analog scale (Mod. 235 of Salter Fairmont MN-USA) fitted on a cage to allow the individual weight check. The feed conversion ratio (FCR) was calculated as proportion of the weight of feed administered over the 40 days interval and the pig weight gain over the same time interval.

\section{Statistical analysis}

The statistical tools used to establish the relationship and difference between the two groups were the ANOVA, the correlation analysis, and frequency analysis by mean of the SAS/STAT ${ }^{\circledR} 2000$ software applying the tools Proc GLM, Proc CORR, Proc FREQ respectively.

\section{Results}

\section{Pig growth performance}

Table 2 shows that on the day of introduction to the fattening unit the pigs of group A (treated) weighed $3 \mathrm{~kg}$ more than the pigs of group B (control) as they were 132 and 125 days old respectively. However, at the weight check in April the average weight of pigs of group A was $5 \mathrm{~kg}$ lower $(\mathrm{P}<0.01)$ than the weight of pigs in group $\mathrm{B}$. In the two last weight check of May and June the pigs of group A showed a significant difference in the average daily weight gain $(\mathrm{P}<0.05)$ however at the third weight check in May the individual average daily weight gain of both groups was reduced passing from an average $800 \mathrm{~g} /$ day to an average $600 \mathrm{~g} /$ day per pig, the FCR did not show any significant difference between the two groups.

\section{Environmental monitoring}

Table 3 shows the mean values of ammonia concentration in barn 4 and 2, which are all lower than the limits $(20 \mathrm{ppm})$ prescribed by the American Conference of Governmental Industrial Hygienists. ${ }^{13}$ During the measurement carried out in June the ammonia concentration in barn 4 housing the treated group (A) was significantly higher $(\mathrm{P}<0.05)$ as the $90 \%$ of the total floor surface was fouled with urine and manure. Table 4 shows the ammonia concentration in the slurry of the treated group A was significantly lower than the value of the control group $\mathrm{B}(\mathrm{P}=0.08)$ whereas the nitrate concentration was almost doubled in the slurry of the treated group $\mathrm{A}(\mathrm{P}<0.01)$.

\section{Discussion}

\section{Pig growth performance}

The average weight check at the beginning of the trial period showed that pigs of group A (treated) were $5 \mathrm{~kg}$ lighter $(\mathrm{P}<0.01)$ than the pigs of group B (control), this significant difference in the first month of growth was probably due to a higher prevalence of cases of colibacillosis in group A. The difference in the daily weight gain in two out of three weight checks $(\mathrm{P}<0.05)$ could be due to an increased daily feed intake of pigs in group A however the FCR did not show any variation between the groups. During the trial the individual average daily weight gain of both groups was progressively reduced over time this can be explained with the physiological decrease of the daily weight gain due to the ageing of animals ${ }^{14}$ and to the progressive increase of the ambient temperature (Table 5) creating unfavorable condition for the productive performance and welfare of the animals. 15

\section{Environmental monitoring}

The atmospheric ammonia concentration was higher in the barn housing pigs of group $\mathrm{A}$ and the ammonia dissolved in the slurry was significantly higher in the samples from group B. This was due to the different excretory behavior of the two groups of pigs.16,17 The pigs of group A did not use the defecation area correctly causing a continuous presence of urine and feces on the floor of barn 4 (Table 4) which masked the possible effect of the additive on

Table 4. Kjeldal nitrogen, nitrate and ammonia concentrations in the slurry.

\begin{tabular}{lcc} 
& Group $\mathrm{A} \pm$ SEM & Group B \pm SEM \\
$\mathrm{KN} \mathrm{g} / 100 \mathrm{~g}$ & $0.52 \pm 0.047$ & $0.52 \pm 0.047$ \\
$\mathrm{NO}_{3} \mathrm{mg} / \mathrm{Kg}$ & $16.5 \pm 2.82^{\mathrm{A}}$ & $8.8 \pm 2.82 \mathrm{~B}$ \\
\hline $\mathrm{NH}_{3} \mathrm{mg} / \mathrm{L}$ & $2952 \pm 163.37 \mathrm{a}$ & $3748 \pm 163.37 \mathrm{~b}$ \\
\hline
\end{tabular}

$\mathrm{KN}$, Kjeldal Nitrogen; $\mathrm{NO}_{3}$, Nitrate; $\mathrm{NH} 3$, Ammonia. a,bMean values in the same row bearing superscript differ for $\mathrm{P}=0.08$. A,BMean values in the same row bearing superscript differ for $\mathrm{P}<0.01$.

Table 5. Ambient temperature and relative humidity in the pig barns.

\begin{tabular}{|c|c|c|c|c|c|c|c|c|}
\hline & & & ture & & & Relative & dity & \\
\hline & & & & & & & & \\
\hline & ${ }^{\circ} \mathrm{C} \pm \mathrm{SD}$ & Min-Max & ${ }^{\circ} \mathrm{C} \pm \mathrm{SD}$ & Min-Max & ${ }^{\circ} \mathrm{C} \pm \mathrm{SD}$ & Min-Max & ${ }^{\circ} \mathrm{C} \pm \mathrm{SD}$ & Min-Max \\
\hline March & $21.9 \pm 2.9$ & $17.5-27.4$ & $21.0 \pm 2.2$ & $16.1-26.5$ & $53 \pm 6$ & $38-67$ & $55 \pm 8$ & $33-78$ \\
\hline April & $26.8 \pm 3.0$ & 20.4-33.4 & $27.3 \pm 1.8$ & $22.5-31.6$ & $75 \pm 9$ & $31-95$ & $78 \pm 7$ & $61-100$ \\
\hline May & $29.0 \pm 3.1$ & $22.5-37.0$ & $29.6 \pm 2.8$ & $23.8-36.2$ & $67 \pm 15$ & $31-100$ & $72 \pm 15$ & $42-100$ \\
\hline June & $29.9 \pm 3.4$ & $23.5-37.8$ & $29.0 \pm 3.2$ & $22-35.8$ & $78 \pm 16$ & $48-100$ & $79 \pm 14$ & $53-100$ \\
\hline July & $28.9 \pm 2.8$ & 23.5-36.7 & $29.4 \pm 3.5$ & $23.0-37.4$ & $62 \pm 7$ & $53-97$ & $58 \pm 9$ & $55-96$ \\
\hline
\end{tabular}


aerial ammonia undermining this aspect of the trial. In fact, according to previous studies, 18 the aerial ammonia concentration is directly depending on the emitting surface covered with urine. In addition the rise of the air temperature and relative humidity contributed to increased ammonia volatilization in both buildings. Thus, from the data obtained, it was not possible to understand if the dosage of the vermiculite in the diet, as recommended by the producer, was sufficient to bind the ammonia and thus reduce the volatilization in the conditions of this trial. The result of the chemical analysis of slurry showed a lower concentration of ammonia in the slurry from the treated group (barn A) whereas the nitrate concentration was significantly higher in the slurry of the treated group (A). The lower ammonia concentration in the slurry is likely to be the consequence of the increased ammonia volatilization, which occurred in barn $A$ as well as with an increased nitrification activity. This increased activity is the probably the reason of higher nitrate concentration in the slurry of barn A and is compatible with the increase of the bacterial activity induced by the vermiculite. ${ }^{19}$ If this were the case the addition of the vermiculite additive would be advisable in slurry system allowing further efficient denitrification, for example anaerobic-aerobic digestion systems. However to clarify this issue further investigation on the influence of treated vermiculite on the chemical pathways leading to nitrification and denitrification in both laboratory and commercial conditions are recommended.

\section{Conclusions}

Analyzing the effects of the inclusion, at very low dosage of vermiculite-based feed additives in fattening pigs, an increase in the nitrification activity in the treated slurry was highlighted. No reduction of the ammonia emission was obtained due mainly to the experimental conditions. The increased nitrification could be exploited to improve the efficiency of manure rendering systems, however further investigation are recommended on the influence of treated vermiculite on the chemical pathways leading to nitrification and denitrifi- cation. The average growth rate of the treated group was higher, whilst the feed conversion rate was similar in both groups. This is of commercial relevance if confirmed by further investigations for instance by including the vermiculite in the diet in combination with multi stage feeding with reduced $\mathrm{CP}$ and energy which should reduce rearing costs whilst maintaining carcass quality.

\section{References}

1. Wathes CM. Environmental control in pig housing. Proceedings of the 15th International Pig Veterinary Society Congress. Birmingham, UK, July 5-9, 1998.

2. Gatel F, Grosjean F. Effect of protein content of the diet on nitrogen excretion by pigs. Livest Prod Sci 1992;31:109.

3. Dourmad JY, Guillou D, Noblet J. Development of a calculation model for predicting the amount of $\mathrm{N}$ excreted by the pig: effect of feeding, physiological stage and performance. Livest Prod Sci 1992;31:95-107.

4. Spiekier H. Possibilities and cost of nitrogen reduction through adapted feeding. In: Klaasen G. ed. Ammonia emission in Europe: emission coefficients and abatement costs. Laxenburg, Austria; 1992. pp 195-210.

5. Kay RM, Lee PA. Ammonia emission from pig buildings and characteristics of slurry produced by pigs offered low crude protein diets. Proceedings of the International Symposium on Ammonia and Odour Control from Animal Production Facilities, Vinkeloord, The Netherlands, Oct 1997. pp 253-60.

6. Kirchgessner M, Kreuzer M, Machmuller A, Roth- Maier DA Evidence for a high efficiency of bacterial protein synthesis in the digestive tract of adult sows fed supplements of fibrous feedstuffs. Anim Feed Sci Technol 1993;46:293.

7. Schulze H, Verstegen MWA, Tamminga S. Effect of increased NDF content in the diet on urinary and faecal nitrogen nitrogen excretion in young growing pigs. In: Verstegen MWA, Den Hartog LA, van Kempen GJM, Metz JHM. eds. Nitrogen
Flow in Pig Production and Environmental Consequences. EAAP Publ. No. 69. Pudoc, Wageningen, Netherlands; 1993. pp 264-7.

8. Canh TT, Verstegen MWA, Aarnink AJA, Schrama JW. Influence of dietary factors on nitrogen partitioning and composition of urine and feces of fattening pigs. J Anim Sci 1997;75:700-6.

9. Shurson GC, Ku PK, Miller ER, Yokoyame MT. Effects of zeolite A or clinoptilolite in diets of growing swine. J Anim Sci 1984;59:1536-45.

10. Poulsen HD, Oksberg N. Effect of dietary inclusion of a zeolite (clinoptilolite) on peformance and protein metabolism of young growing pigs. Anim Feed Sci Technol 1995;53:297-303.

11. A.O.A.C. Official Methods of Analysis. 11 th ed. Association of Official Agricultural Chemists. Washington D.C. 1990.

12. Perkin-Elmer C. High Pressure Liquid Chromatography Analytical Methods. 1996.

13. ACGIH Am. Conf. Gov. Ind. Hygienists. Threshold limit values for chemical substances and physical agents and biological exposure indices. Cincinnati, Ohio; 1993.

14. Webster AJF. The energetic efficiency of growth. Livest Prod Sci 1980;7:243-52.

15. Aarnink AJA, Schrama JW, Heetkamp MJW. Temperature and body weight affect fouling of pig pens. J Anim Sci 2006;84:222431 .

16. Aarnink AJA, Keen A, Metz JHM, et al. Ammonia emission patterns during the growing periods of pigs housed on partially slatted floors. J Agric Eng Res 1995;62:105-16.

17. Ni JQ, Vinckier C, Coenegrachts J, Hendriks J. Effect of manure on ammonia emission from a fattening pig house with partly slatted floor. Livest Prod Sci 1999;59:25-31.

18. Geeta GS, Raghavendra S, Reddy R. Increase in biogas production from bovine excreta by addition of various inert materials. Agric Waster 1986;17:153-6.

19. Aarnink AJA, Swierstra D, Van den Berg AJ, Speelman L. Effect of type of slatted floor and degree of fouling of solid floor on ammonia emission rates from fattening piggeries. J Agric Eng Res 1997;66:93-102. 